REIMPRESIONES

Rev Chil Salud Pública 2013

Vol 17 (1): 78-80

\title{
Tegualda Monreal Porcile (1917-2012) y el aborto en Chile
}

El 27 de diciembre de 2012 falleció Tegualda Monreal Porcile. Epidemióloga destacada y trabajadora incansable, su vida profesional se extiende entre 1944 -año de su graduación- hasta el 2006 en que se retira habiéndose desempeñado en los últimos años como epidemióloga en el Servicio de Salud Metropolitano Occidente. Su larga y fructífera vida profesional fue dividida, como la de tantos otros, por el golpe de estado que la arrancó de Chile, con largas estadías en Estados Unidos y Mozambique.

A propósito de su valiosa y productiva vida, en este número de la Revista Chilena de Salud Pública queremos destacar dos publicaciones. Por una parte, el artículo de Tegualda Monreal "Aborto y legislación" del año 1973, que reimprimimos en esta ocasión y al que haremos referencia más adelante, y por otra parte el libro "Historia de Vida Tegualda Monreal. Un acervo multimedia de testimonios orales" preparado por Unidad de Patrimonio Cultural de la Salud bajo la dirección de Carlos Molina Bustos $^{1}$. El primero es un texto de la propia autora que da cuenta de su posición en los debates de su tiempo, es decir un material del primer nivel 'geológico' del mundo social; y el segundo un comentario desde nuestros días y concepciones actuales acerca de esa vida y esa obra: un material del segundo nivel 'geológico'.

Tegualda Monreal se incorpora a la Escuela de Salubridad, y específicamente a la Cátedra de Epidemiología, en julio de 1960. Desde ese momento empieza a trabajar en la investigación poblacional sobre el aborto en Santiago, la que terminará publicándose como "Epidemiología del Aborto Provocado en Santiago", en la Revista Chilena de Obstetricia y Ginecología en 1964. Se trata al parecer del primer estudio en el mundo en que el aborto fue estudiado en población general; hasta esa fecha todas las investigaciones sobre el tema se limitaban a estudios en mujeres hospitalizadas a raíz de las habituales complicaciones del aborto provocado en condiciones muy distantes de la asepsia requerida. Como lo han destacado muchos, se trata de un estudio pionero, visionario y atrevido al tratar con rigor un tema entonces y hoy controvertido que permitió incrementar conciencias y experiencias en el campo de la salud reproductiva de la mujer. Aníbal Faúndez destaca con certeza que trabajos de este tipo incidieron en que un presidente

Sociólogo. Magister en Ciencia Política. Editor Asociado Revista Chilena de Salud Pública jagaetea@gmail.com
1. Carlos Molina Bustos "Historia de Vida Tegualda Monreal. Un acervo multimedia de testimonios orales", Ministerio de Salud, Unidad de Patrimonio Cultural, 2009, 298 páginas. 
católico como Frei Montalva con un ministro tachado de conservador como Ramón Valdivieso crearan las condiciones que permitieron la más amplia oferta de métodos anticonceptivos a la población a través del SNS. De hecho, este estudio consagró a Tegualda Monreal en la epidemiología nacional.

Pero el hecho que fuera el primer estudio realizado en población general es desconocido por su autora. El siguiente diálogo forma parte de "Historia de vida Tegualda Monreal". Carlos Molina le pregunta: "...que no hubiere estudios epidemiológicos muestrales sobre el aborto, ¿es una de las razones por las que tú hiciste esta investigación?", Tegualda Monreal responde: "Yo no sabía que no hubiera habido otros trabajos en el mundo, porque tampoco tenía acceso"; CM: "Tú no sabias que era inédita, que no se habia hecho antes?"; TM: "No tenía ninguna idea. Me lei todos los trabajos que conocí; eran todos hospitalarios, de médicos especialistas en ginecología y obstetricia."

Esta investigación sobre el aborto pareciera realizarse en una situación de orfandad bastante acentuada, por lo que relata Tegualda Monreal en ese libro. "Nunca en la vida habia hecho un estudio epidemiológico de nada" (p 225); "Estaba empezando la epidemiología. La Escuela de Salud Pública se creó el año 44 pero el año 44 recién se iniciaba, no habia suficientes médicos, no habia alumnos ni nada..." (p 226); “... yo no me acuerdo haber recibido alguna información sobre cómo realizar una investigación, las etapas de una investigación, porque eso es muy posterior" (pp 226-7).

Cierto es que hace 50 ó 60 años todo estaba empezando: la Escuela de Salud Pública, la investigación en Salud Pública, la epidemiología. Sin embargo, también es cierto que antes que se realizara este estudio sobre el aborto, ya existía un fuerte movimiento académico e institucional en torno a la necesidad de reducir el aborto provocado. Ya existía la Unidad Sanitaria de Quinta Normal, Benjamín Viel y Mariano Requena, Hernán Romero y Onofre Avendaño. Por cierto, el Servicio Nacional de Salud había ya incorporado la regulación de la natalidad en su programación habitual. El SNS tenía entonces sólida presencia normativa y operativa y las relaciones docente-asistenciales con la Universidad de Chile garantizaban la formación de un eficiente personal de salud. El incipiente Comité de Protección de la Familia daba lugar a la Asociación Chilena de Protección de la Familia (APROFA), y se transformaba en apoyo, sobre todo material, a este tipo de actividades cuando el SNS se marginaba. En 1967 se celebraría en Santiago la 8 ${ }^{a}$ Conferencia Internacional de la Federación Internacional de Planificación de la Familia, en que el Gobierno chileno respaldaría las acciones en favor del control de la natalidad ${ }^{2}$. En otro orden temático tengamos presente igualmente que ya existen algunas publicaciones señeras en el campo de la salud pública nacional. Por ejemplo, el libro de Hugo Behm "Mortalidad infantil y nivel de vida" publicado por Editorial Universitaria en 1962, y el de Benjamin Viel "La explosión demográfica", Editorial Universitaria 1966.

Estos antecedentes llevan a que uno se pregunte cómo era realmente la vida académica en esos años, cómo era la salud pública en ese entonces ${ }^{3}$. ¿Se trabajaba realmente en esa orfandad que creemos derivar de las confesiones de Tegualda Monreal? La expresión 'realmente' no quiere decir aquí 'de una manera conclusiva', 'con la evidencia de una demostración'. Mi intención no es otra que advertir las sinuosidades del terreno. Es más, casi no creo que 'realmente' sea un adverbio usable con propiedad.

Trabajar en la interpretación de materiales de primer grado, involucra una tarea que de cuenta

2. Jadwiga Pieper Mooney proporciona abundantes antecedentes acerca de estas experiencias en su artículo "Salvar vidas y gestar la modernidad: médicos, mujeres y Programas de Planificación Familiar en Chile" en MS Zárate "La salud del cuerpo. Historias y políticas sanitarias en Chile", Ediciones Universidad Alberto Hurtado, Santiago 2008. Revísese también Jorge Rosselot "Regulación de la natalidad en el Servicio Nacional de Salud", Cuad Med Soc, Vol 16 №2, 1966.

3. Las preguntas que siguen parten de una consideración metodológica general y que tiene que ver con el papel de la experiencia en análisis de este tipo. EP Thompson lo dirá en su estilo único: "La experiencia no espera discretamente a la puerta de sus despachos, a la expectativa del momento en que el discurso de la demostración la invitará a pasar. La experiencia penetra sin llamar a la puerta, anunciando muertos, crisis de subsistencia, guerras de trincheras, paro, inflación, genocidio. Hay gente que muere de hambre: los sobrevivientes inquieren sobre nuevas maneras de hacer funcionar el mercado..." (EP Thompson, Miseria de la Teoría, pag 21, citado por Sorgentini, H. (2000) "La recuperación de la experiencia histórica: Un comentario sobre E.P. Thompson" [en línea]. Sociohistórica 7. Disponible en http://www.fuentesmemoria.fahce.unlp.edu.ar/art_revistas/pr.2820/pr.2820.pdf). En este caso, se trata de algo indudablemente menos dramático: la experiencia apunta a un particular estado del desarrollo teórico de la salud pública en que vivía el mundo académico en los 60 . 
de los 'hechos', hasta donde éstos puedan ser construidos y descritos propiamente, y además intentan dar cuenta de las intenciones y voluntades de los sujetos involucrados. Desde una perspectiva así, ¿cómo entender entonces el esfuerzo grande de Tegualda Monreal para definir un proyecto de ese tipo?, ¿cómo entender la naturaleza del proyecto, la metodología empleada, el análisis efectuado?, ¡cómo entender la simpleza de la línea desarrollada y la enorme significación de sus resultados? No hacer este esfuerzo, dejar estas preguntas a un lado, es perpetuar un análisis ya consagrado, repetir de modo invariable el discurso de la demostración y estar condenados a no avanzar un ápice en el desarrollo conceptual de la salud pública nacional. En el fondo, hacer un homenaje que se diluye tan pronto se termina. No se construye nada.

Ciertamente tomar en serio ese programa excede el objetivo de estas páginas. De todas formas, digamos que ciertamente era otra época. En nuestro país, al menos, no se conocía gran cosa de la epistemología. Lo nuestro era la política; el mundo nuevo estaba al alcance de la mano. Rechazábamos por cierto el positivismo, pero la metodología de investigación de la que nos habían atosigado -al menos a los sociólogos- no nos permitía una reflexión mayor acerca de lo que hacíamos. El compromiso político, omnipresente en todo orden de cosas pero más aún en las 'torres de cristal' en las que vivíamos, ordenaba nuestras vidas y sustituía a esa reflexión. Y así, cándidamente, investigábamos y avanzábamos. Avanzamos y nos acercamos a ese nuevo mundo, pero este avance tal vez por su misma candidez demostró sus limitaciones, y la experiencia histórica de unos años después lo demostró a la saciedad.

El artículo de Tegualda Monreal que reimprimimos en esta ocasión es "Aborto y legisla- ción”, una presentación suya en la Sociedad Chilena de Obstetricia y Ginecología que tuvo lugar el 17 de abril de 1973 y que fuera luego publicado en la Revista Chilena de Obstetricia y Ginecología, Vol. 37 No 2 de 1973.

¿Cuál es la importancia que le atribuimos a este artículo? Por una parte, la precisión con que se plantea el tema: el aborto se visualiza en un ámbito de liberación paulatina, con objetivos limitados, en casos concretos, y dentro de un marco que no abandona la idea general de la protección de la familia. En segundo lugar, porque la autora conoce el lugar desde donde habla: no se trata de una política natalista, no va a resolver situaciones socioeconómicas que se lograrán por otras acciones del gobierno popular, se limita a casos que un espíritu libre de prejuicios debe aceptar. Por último, por su claridad para plantear que en la nueva sociedad que se estaba construyendo pronto el aborto dejaría de ser un tema de la salud pública para retornar en el ámbito de la vida privada de la mujer o de la pareja.

Pero, por otra parte, también es importante porque así, a través del debate, es como se avanza. Dispositivos como éste, el presentar un tema a la discusión en el seno de una sociedad médica, son parte de una larga cadena de deliberaciones que van contrastando opiniones y reflexiones cuya modificación será en definitiva más concluyente que los datos escuetos de una muestra poblacional.

La argumentación ofrecida no varía gran cosa de lo que se plantea hoy día. Quizás una indicación que temas como este del aborto tiene vinculaciones tan profundas que el cambio de criterios es una cosa difícil de lograr. No es, en todo caso, ajeno a lo que ocurre con buena parte de la salud pública, que muestran que la reflexión es un imperativo. 